\title{
Welcome Message from the Congress President
}

\author{
Dear Friends, Dear Colleagues, Dear Guests
}

It was a great pleasure for me to announce that the 1st meeting of the International Phototherapy Association (IPTA) would be held from July 1st to 2nd 2006, in Suwa City in the beautiful Japanese Alps of Nagano Prefecture, a recent host of the Winter Olympics. Now you are here, it is an even greater pleasure! Suwa City is famous as a summer resort and is situated on a beautiful plateau, with a lake and fantastic hot springs. I am particularly honoured that the IPTA will hold its first congress as a joint meeting with the 18th annual congress of the Japan Laser Therapy asso-

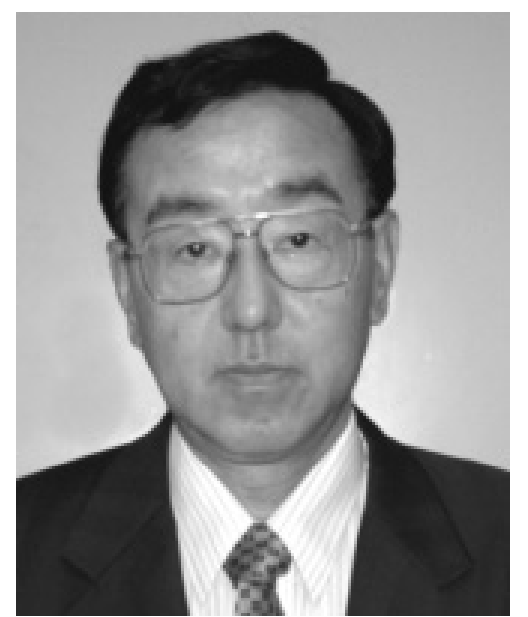

Yoshimi Asagai MD ciation (JaLTA)

These days, many more papers on light therapy, or phototherapy, using high intensity light-emitting diodes (LEDs) and photodynamic therapy (PDT) are appearing in the international literature in addition to phototherapy with lasers. Driven by this situation, we have decided to establish a new academic society, the International Phototherapy Association (IPTA), and I am very proud, and honoured, to be the president of the inaugural congress of this new society.

Looking to the future, Professor Ronald Wheeland (USA) who served as the president of the American Society for Laser Medicine and Surgery (ASLMS) between 1993 and 1994, has accepted the post of IPTA President-Elect, and so, in 2007, he will hold the 2nd IPTA congress in the USA. We look forward to the increase of IPTA members in the USA. The journal Laser Therapy has become the official journal of IPTA. Professor Wheeland is one of the co-editor of this journal. From Volume 15 of this journal, we are happy to welcome Professor Harubumi Kato (Japan) to the journal Editorial Board, one of the world leaders in photodynamic therapy.

I am very proud to be holding the 1st congress of the IPTA in the marvelous nature of Nagano prefecture. The Organizing Committee and I look forward to your active and rewarding participation!

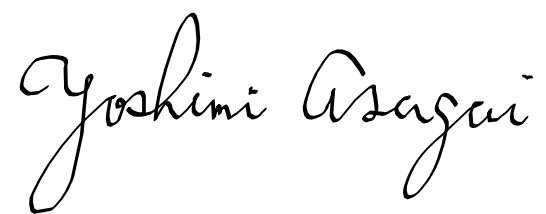

Yoshimi Asagai, MD

Congress President, 1st Congress of the IPTA 